\title{
CMIP5 Projected Change in Northern Hemisphere Winter Cyclones with Associated Extreme Winds
}

\author{
EDMUND KAR-MAN CHANG \\ School of Marine and Atmospheric Sciences, Stony Brook University, State University of New York, \\ Stony Brook, New York
}

(Manuscript received 27 December 2017, in final form 17 April 2018)

\begin{abstract}
In this study, 19 simulations from phase 5 of the Coupled Model Intercomparison Project (CMIP5) have been analyzed to examine how winter cyclones producing extreme near-surface winds are projected to change. Extreme wind thresholds correspond to a top 5 or top 1 cyclone per winter month in the entire Northern Hemisphere (NH). The results show that CMIP5 models project a significant decrease in the number of such cyclones, with a 19 -model mean decrease of about $17 \%$ for the entire NH toward the end of the twenty-first century, under the high-emission RCP8.5 scenario. The projected decrease is larger in the Atlantic (about 21\%). Over the Pacific, apart from an overall decrease (about 13\%), there is a northeastward shift in the extreme cyclone activity. Less decrease is found in the frequency of cyclones producing extreme winds at $850 \mathrm{hPa}$ (about $5 \%$ hemisphere-wide), with models mainly projecting a northeastward shift in the Pacific. These results suggest that $850-\mathrm{hPa}$ wind changes may not be a good proxy for near-surface wind changes. These results contrast with those for the Southern Hemisphere, in which the frequency of cyclones with extreme winds are projected to significantly increase in all four seasons.
\end{abstract}

\section{Introduction}

Extratropical cyclones give rise to much of the highimpact weather in the midlatitudes, including heavy precipitation, strong winds, and extreme cold temperature events (e.g., Kunkel et al. 2012; Ma and Chang 2017). Thus how they will change in the future is of great concern. With global warming, increased moisture in the atmosphere is expected to give rise to more cyclonerelated precipitation (e.g., Bengtsson et al. 2009; Zappa et al. 2013). However, how extreme winds related to cyclones might change is still an open question. According to the Fifth Assessment Report (AR5) of the Intergovernmental Panel on Climate Change (IPCC; Christensen et al. 2013): "The CMIP5 [phase 5 of the Coupled Model Intercomparison Project] model projections show little evidence of change in the intensity of winds associated with ETCs [extratropical cyclones]." Nevertheless, few studies have examined multimodel ensemble projections of how cyclone-related winds may change, and those that did mainly examined winds at $850 \mathrm{hPa}$ in the Northern Hemisphere (NH; e.g., Zappa et al. 2013).

Corresponding author: Dr. Edmund K. M. Chang, kar.chang@ stonybrook.edu
Recently, Chang (2017) examined how extreme cyclones are projected to change by CMIP5 models in the Southern Hemisphere ( $\mathrm{SH}$ ) and found that the number of cyclones with extreme near-surface winds is projected to significantly increase in all four seasons, with a projected multimodel mean increase of about $+20 \%$ in the cool seasons between the end of the twentieth and twenty-first centuries under the high-emission representative concentration pathway (RCP) 8.5 scenario. Even larger projected increases (over $40 \%$ ) are found at $850 \mathrm{hPa}$. These increases are likely due to the projected increase in upper-tropospheric baroclinicity, due to enhanced upper-tropospheric warming in the tropics and subtropics, and cooling in the lower stratosphere (e.g., Yin 2005; Christensen et al. 2013).

The situation is less clear in the NH. Similar to the SH, upper-level baroclinicity is expected to increase. However, near the surface, enhanced high-latitude warming (e.g., Holland and Bitz 2003) is expected to give rise to decreases in low-level baroclinicity, counteracting the upper-level increase (e.g., Harvey et al. 2014). In response to these changes, several studies have suggested an increase in storm-track activity (in terms of variance statistics) in the upper troposphere, but a decrease in the lower troposphere (e.g., Chang et al. 2012; Harvey et al. 
TABLE 1. List of CMIP5 models analyzed in this study. Models A1-A7 have only provided 850-hPa winds but not model-level nearsurface winds.

\begin{tabular}{|c|c|c|}
\hline Model No. & CMIP5 model & Modeling center or group \\
\hline 1 & ACCESS1-3 & $\begin{array}{l}\text { Commonwealth Scientific and Industrial Research Organization and Bureau of Meteorology, } \\
\text { Australia (CSIRO-BOM) }\end{array}$ \\
\hline 2 & BCC_CSM1.1 & Beijing Climate Center, China Meteorological Administration, China (BCC) \\
\hline 3 & BCC_CSM1.1(m) & \\
\hline 4 & CanESM2 & $\begin{array}{l}\text { Canadian Centre for Climate Modeling and Analysis, Victoria, British Columbia, Canada } \\
\text { (CCCma) }\end{array}$ \\
\hline 5 & CCSM4 & National Center for Atmospheric Research, Boulder, Colorado (NCAR) \\
\hline 6 & CMCC-CM & Centro Euro-Mediterraneo sui Cambiamenti Climatici, Lecce, Italy \\
\hline 7 & CSIRO-Mk3-6-0 & $\begin{array}{l}\text { Australian Commonwealth Scientific and Industrial Research Organization Marine and } \\
\text { Atmospheric Research in collaboration with the Queensland Climate Change Centre of } \\
\text { Excellence, Australia }\end{array}$ \\
\hline 8 & GFDL-CM3 & NOAA Geophysical Fluid Dynamics Laboratory, Princeton, New Jersey \\
\hline 9 & GFDL-ESM2G & \\
\hline 10 & GFDL-ESM2M & \\
\hline 11 & HadGEM2-ES & Met Office Hadley Centre, United Kingdom \\
\hline 12 & IPSL-CM5A-LR & Institute Pierre Simon Laplace, Paris, France \\
\hline 13 & IPSL-CM5A-MR & \\
\hline 14 & IPSL-CM5B-LR & \\
\hline 15 & MIROC5 & Atmosphere and Ocean Research Institute, The University of Tokyo, and National Institute \\
\hline 16 & MIROC-ESM & for Environmental Studies and Japan Agency for Marine-Earth Science and Technology \\
\hline 17 & MIROC-ESM-CHEM & \\
\hline 18 & MRI-CGCM3 & Meteorological Research Institute, Tsukuba, Japan \\
\hline 19 & NorESM1-M & Norwegian Climate Centre, Bergen, Norway \\
\hline A1 & CNRM-CM5 & $\begin{array}{l}\text { Centre National de Recherches Meteorologiques and Centre Europeen de Recherches et } \\
\text { de Formation Avancee en Calcul Scientifique, Toulouse, France }\end{array}$ \\
\hline $\mathrm{A} 2$ & FGOALS-g2 & $\begin{array}{l}\text { Institute of Atmospheric Physics, Chinese Academy of Sciences and Tsinghua University, } \\
\text { China }\end{array}$ \\
\hline A3 & HadGEM2-CC & Met Office Hadley Centre, United Kingdom \\
\hline A4 & INM-CM4 & Institute of Numerical Mathematics, Moscow, Russia \\
\hline A5 & MPI-ESM-LR & Max Planck Institute for Meteorology, Hamburg, Germany \\
\hline A6 & MPI-ESM-MR & \\
\hline A7 & MRI-ESM1 & Meteorological Research Institute, Tsukuba, Japan \\
\hline
\end{tabular}

2012). In fact, several studies have found hints of a decrease in $\mathrm{NH}$ extratropical cyclone activity associated with the recent accelerated high-latitude warming (e.g., Coumou et al. 2015; Chang et al. 2016; Wang et al. 2017).

Regarding intense surface cyclones, Chang et al. (2012) found that CMIP5 models project a decrease in the frequency of deep cyclones in the $\mathrm{NH}$ with cyclone depth defined based on sea level pressure (SLP) anomalies (i.e., deviations from a large-scale, low-frequency background). On the other hand, Mizuta (2012), defining cyclone intensity based on the absolute SLP value, found an increase in the frequency of deep winter cyclones, especially over the Pacific. Chang (2014) investigated the reason behind these different findings and showed that the difference is mainly due to a projected deepening of the seasonal mean Aleutian low. Zappa et al. (2013) examined CMIP5 projections over the Atlantic and found that there is a slight basinwide reduction in the number of cyclones with strong $850-\mathrm{hPa}$ winds. However, there is an increase in the frequency of cyclones with high precipitation. More recently, Seiler and Zwiers (2016) found a projected decrease in the number of explosive cyclones in the Atlantic but mainly a northeastward shift in the Pacific. Thus there are conflicting results depending on how intense cyclones are defined. Given that one important impact of cyclones is strong near-surface winds, and none of the aforementioned studies examined extreme cyclones defined in terms of cyclone-related near-surface winds, this study will focus on addressing this issue.

\section{Data and methods}

The main data source is the multimodel ensemble data obtained from the CMIP5 data archive. To examine near-surface winds, 6-hourly model-level data from the lowest model level ( $u$ and $v$ ) are used. Data from 19 models from 12 modeling centers are available (Table 1 ) covering the historical (1980-99) and future (2081-2100) periods. These are the same set of models used to examine SH projections by Chang (2017). Some characteristics of each model are listed in Table 2. These 19 
TABLE 2. Lowest model level (sigma or $\mathrm{m}$ ) and horizontal grid spacing $\left(^{\circ}\right)$. The approximate equivalent height of the model sigma levels are also given inside the parentheses.

\begin{tabular}{|c|c|c|c|c|}
\hline \multirow[b]{2}{*}{ Model No. } & \multirow[b]{2}{*}{ CMIP5 model } & \multirow[b]{2}{*}{ Lowest model level } & \multicolumn{2}{|c|}{ Horizontal grid spacing } \\
\hline & & & Lon $\left(^{\circ}\right)$ & Lat $\left(^{\circ}\right)$ \\
\hline 1 & ACCESS1-3 & $10 \mathrm{~m}$ & 1.875 & 1.25 \\
\hline 2 & BCC_CSM1.1 & $0.9926(61 \mathrm{~m})$ & 2.8125 & 2.8125 \\
\hline 3 & BCC_CSM1.1(m) & $0.9926(61 \mathrm{~m})$ & 1.125 & 1.125 \\
\hline 4 & CanESM2 & $0.9950(41 \mathrm{~m})$ & 2.8125 & 2.8125 \\
\hline 5 & CCSM4 & $0.9926(61 \mathrm{~m})$ & 1.25 & 0.9375 \\
\hline 6 & CMCC-CM & $0.9961(32 \mathrm{~m})$ & 0.75 & 0.75 \\
\hline 7 & CSIRO-Mk3-6-0 & $0.9955(37 \mathrm{~m})$ & 1.875 & 1.875 \\
\hline 8 & GFDL-CM3 & $0.9961(32 \mathrm{~m})$ & 2.5 & 2 \\
\hline 9 & GFDL-ESM2G & $0.9961(32 \mathrm{~m})$ & 2.5 & 2 \\
\hline 10 & GFDL-ESM2M & $0.9961(32 \mathrm{~m})$ & 2.5 & 2 \\
\hline 11 & HadGEM2-ES & $10 \mathrm{~m}$ & 1.875 & 1.25 \\
\hline 12 & IPSL-CM5A-LR & $0.9958(34 \mathrm{~m})$ & 3.75 & 1.875 \\
\hline 13 & IPSL-CM5A-MR & $0.9958(34 \mathrm{~m})$ & 2.5 & 1.26 \\
\hline 14 & IPSL-CM5B-LR & $0.9958(34 \mathrm{~m})$ & 3.75 & 1.875 \\
\hline 15 & MIROC5 & $0.9964(29 \mathrm{~m})$ & 1.40625 & 1.40625 \\
\hline 16 & MIROC-ESM & $0.9950(41 \mathrm{~m})$ & 2.8125 & 2.8125 \\
\hline 17 & MIROC-ESM-CHEM & $0.9950(41 \mathrm{~m})$ & 2.8125 & 2.8125 \\
\hline 18 & MRI-CGCM3 & $0.9950(41 \mathrm{~m})$ & 1.125 & 1.125 \\
\hline 19 & NorESM1-M & $0.9926(61 \mathrm{~m})$ & 2.5 & 1.875 \\
\hline
\end{tabular}

models sample both structural and climatological uncertainties. Among these 19 models, 12 provided derived 10-m winds. Similar analyses have been conducted using the 10-m winds in place of the lowest model-level wind, and the results are very similar and will be briefly discussed in the appendix. For future projection, the highemission RCP8.5 scenario is examined to maximize the projected signal. Since most models only provide modellevel data from a single ensemble member, only one member has been examined from each model. Six-hourly pressure-level data, including $850-\mathrm{hPa}$ wind and SLP, are also used. The analyses in this study will focus on the $\mathrm{NH}$ extended winter season (from November to March), thus including 100 months of data for each period. Reanalysis data from the European Center for Medium-Range Weather Forecasts (ECMWF) interim reanalysis (ERAInterim) from the historical period have also been used for comparison with model climatology. ERA-Interim data are analyzed at a resolution of $1.5^{\circ} \times 1.5^{\circ}$.

Cyclones are tracked using the objective tracking algorithm developed by Hodges (1999). Since this algorithm has been used by many previous studies, here only a brief description will be provided, and readers are referred to Hodges (1999) and Hoskins and Hodges (2002) for further details about the algorithm and to Chang (2017) for our specific implementation. Two definitions of cyclones are considered: minima in SLP and maxima in $850-\mathrm{hPa}$ relative vorticity. The SLP and vorticity data are separated into monthly segments for the tracking. For $850-\mathrm{hPa}$ relative vorticity, to focus on synoptic-scale mobile cyclones, only scales equivalent to a spherical harmonic triangular truncation of between T5 and T42 are kept (Hoskins and Hodges 2002). For SLP, following Chang (2014, 2017), both large-spatial-scale (total wavenumber less than T5) and monthly mean SLP are removed. To focus on mobile cyclones, only tracks that last at least two days and with displacement larger than $1000 \mathrm{~km}$ are retained. Previous studies (e.g., Raible et al. 2008; Neu et al. 2013) have suggested that while there are uncertainties in cyclone statistics arising from different detection and tracking methods, the statistics of strong cyclones are robust. Since we focus on extreme cyclones, we expect that our results should not be sensitive to the tracking algorithm.

Based on SLP minima, on average there are about 108 cyclones per month found in ERA-Interim data. During the historical period, CMIP5 models simulate a range between 86 and 121 cyclones per month, with a multimodel mean of about 105 cyclones. For 850 -hPa vorticity maxima, ERA-Interim has on average about $154 \mathrm{cy}-$ clones per month. CMIP5 models simulate a range between 133 and 214 cyclones per month, with an average of about 159 cyclones.

Cyclone intensity is defined based on the maximum wind speed within 5 great circle degrees from a cyclone center. Extreme cyclones are defined by the wind speed threshold corresponding to a top 5 or top 1 cyclone per month for the $\mathrm{NH}$ as a whole. These thresholds are listed in Table 3. Note that since there are on the order of 100 cyclones per month, these thresholds correspond roughly to the top 5 or top 1 percentile of cyclones. As 
TABLE 3. Threshold wind speed $\left(\mathrm{m} \mathrm{s}^{-1}\right.$ ) for top 5 and top 1 cyclones (per winter month) for each model, defined based on maximum $850-\mathrm{hPa}$, near-surface, and 10-m wind speed within $555 \mathrm{~km}$ of the cyclone center.

\begin{tabular}{|c|c|c|c|c|c|c|}
\hline \multirow[b]{2}{*}{ Model No. } & \multirow[b]{2}{*}{ CMIP5 model } & \multicolumn{2}{|c|}{ Near-surface wind } & \multicolumn{2}{|c|}{ 850-hPa wind } & \multirow{2}{*}{$\frac{10-\mathrm{m} \text { wind }}{\text { Top } 5}$} \\
\hline & & Top 5 & Top 1 & Top 5 & Top 1 & \\
\hline & ERA-Interim & 27.7 & 32.0 & 45.3 & 50.5 & 27.7 \\
\hline 1 & ACCESS1-3 & 25.2 & 28.2 & 42.4 & 48.0 & 24.3 \\
\hline 2 & BCC_CSM1.1 & 35.7 & 40.8 & 47.0 & 54.3 & \\
\hline 3 & BCC_CSM1.1(m) & 40.3 & 45.2 & 52.6 & 58.7 & 29.7 \\
\hline 4 & CanESM2 & 26.8 & 30.0 & 42.5 & 48.0 & \\
\hline 5 & CCSM4 & 35.1 & 39.3 & 44.5 & 49.7 & \\
\hline 6 & CMCC-CM & 33.9 & 38.2 & 47.2 & 52.5 & 29.9 \\
\hline 7 & CSIRO-Mk3-6-0 & 31.1 & 36.4 & 39.7 & 44.3 & \\
\hline 8 & GFDL-CM3 & 29.4 & 32.8 & 44.0 & 50.3 & 25.6 \\
\hline 9 & GFDL-ESM2G & 28.4 & 32.1 & 40.9 & 47.3 & 25.4 \\
\hline 10 & GFDL-ESM2M & 27.6 & 31.2 & 40.2 & 46.8 & 24.5 \\
\hline 11 & HadESM2-ES & 25.7 & 28.5 & 42.8 & 48.7 & \\
\hline 12 & IPSL-CM5A-LR & 25.7 & 29.8 & 42.1 & 49.1 & 21.8 \\
\hline 13 & IPSL-CM5A-MR & 27.8 & 34.2 & 45.3 & 52.3 & 24.0 \\
\hline 14 & IPSL-CM5B-LR & 27.4 & 30.7 & 43.3 & 48.7 & \\
\hline 15 & MIROC5 & 30.4 & 33.9 & 42.3 & 48.5 & 30.8 \\
\hline 16 & MIROC-ESM & 41.9 & 47.7 & 50.0 & 57.6 & 24.4 \\
\hline 17 & MIROC-ESM-CHEM & 42.2 & 48.6 & 50.8 & 57.9 & 24.6 \\
\hline 18 & MRI-CGCM3 & 47.2 & 60.5 & 48.2 & 55.3 & 40.8 \\
\hline 19 & NorESM1-M & 30.5 & 34.5 & 38.8 & 43.9 & \\
\hline
\end{tabular}

discussed in Chang (2017), given that the height of the lowest model level varies from 10 to about $60 \mathrm{~m}$ above the surface (see Table 2), a constant threshold across all models is not meaningful, and extreme cyclones for each model should be defined based on its own climatology. Since there are 100 months of data for each period, there are 500 top 5 cyclones in the historical period, which should give rather stable statistics. In addition, the use of the 19-model ensemble also samples climate variability, and agreement among the model projections would indicate that results are robust both to climate variability and model physics. The positions of cyclone centers defined by SLP minima are used for finding the maximum near-surface wind, while the positions of centers defined by $850-\mathrm{hPa}$ vorticity maxima are used for the maximum $850-\mathrm{hPa}$ wind. However, results are similar if only cyclone centers from one level are used.

The highest frequency of occurrence of the extreme near-surface winds is in the vicinity of Greenland (see Figs. 1d,e) associated with the tip jet (e.g., Våge et al. 2009) and the katabatic circulation (e.g., Gorter et al. 2014). These extreme winds are related to the interaction between the atmospheric circulation and the steep topography, which is not expected to be well resolved by the CMIP5 global models. Hence a mask has been used to mask out regions in the vicinity of Greenland (orange shading in Fig. 1d) such that winds over the region are not included in the analysis. Nevertheless, as we will show later, including winds over the masked area does not change the conclusion of this study.

To quantify extreme cyclone statistics, we examine the average number of cyclone tracks per month for the historical period and future projection. For this statistic, each cyclone track that exceeds the threshold is counted only once. To display the spatial distribution, the frequency (as a percentage of time) of occurrence of cyclone centers that exceeds the threshold within $500 \mathrm{~km}$ of the center of each grid box is displayed on a common $2.5^{\circ} \times 2.5^{\circ}$ grid. In this case, each instance that a cyclone center exceeds the threshold is counted, so a single cyclone track can be counted multiple times. This measure is similar to the feature density of Hoskins and Hodges (2002).

As discussed above, previous studies have suggested that cyclone track statistics might be sensitive to the tracking algorithm used to track the cyclones. Thus it is of interest to examine the extreme wind statistics themselves. For each model (as well as ERA-Interim), the frequency of occurrence of wind above the threshold of a top 5 cyclone (Table 3 ) at each grid box, as well as its projected change, are computed at its native grid. These statistics are then linearly interpolated onto a common $2.5^{\circ} \times 2.5^{\circ}$ grid for computation of a multimodel mean. Note that based on ERA-Interim data, over $60 \%$ of extreme winds $\left(10-\mathrm{m}\right.$ wind speed $\left.>27.7 \mathrm{~m} \mathrm{~s}^{-1}\right)$ occur within 5 great circle degrees of a cyclone center, and over $86 \%$ occur within 10 great circle degrees. Thus one would expect that the statistics of extreme winds and 


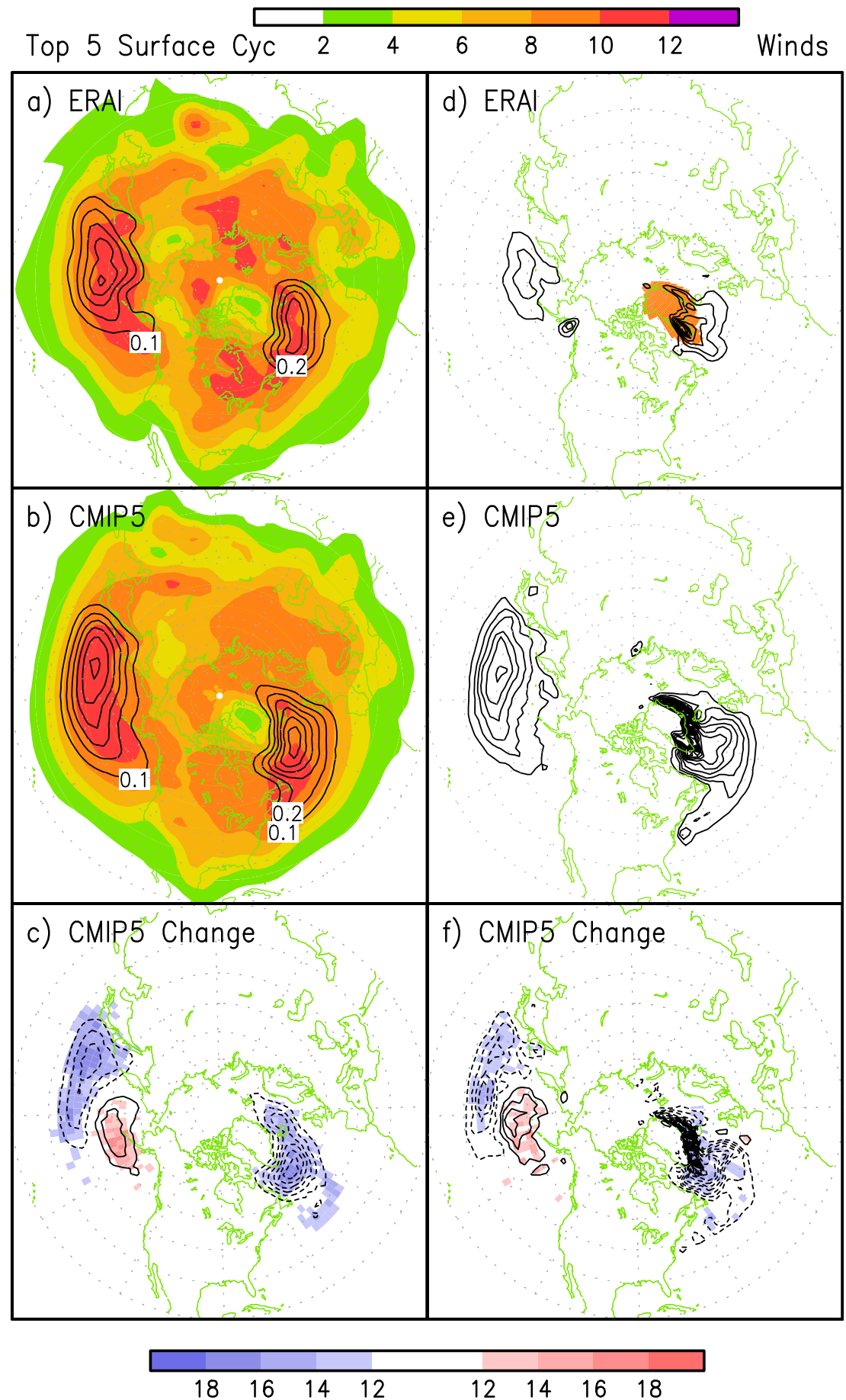

FIG. 1. (a) Climatology of cyclone frequency for all cyclones (shading in top color bar; \%) and cyclones with extreme near-surface winds (corresponding to a top 5 cyclone per winter month; contours; contour interval is $0.1 \%$ ), based on ERA-Interim data. (b) As in (a) but for the CMIP5 multimodel mean. (c) Projected change in cyclone frequency (contour interval is $0.05 \%)$. (d)-(f) As in (a)-(c), but for frequency of extreme winds corresponding to a top 5 cyclone [contour interval is $0.02 \%$ in (d) and (e) and $0.01 \%$ in (f).] Shading in (c) and (f) shows the number of models projecting the same sign of change, with blue shades for a decrease and pink shades for an increase. Orange shading in (d) shows the Greenland mask and strong winds within this region are not included. Note that ERA-Interim data have been smoothed using a 9-point $(3 \times 3)$ filter to facilitate comparison with the multimodel ensemble mean. 
those of cyclones with extreme winds to be highly correlated with each other.

\section{Results}

\section{a. Cyclones with extreme near-surface winds}

The climatological distribution of cyclone frequency for top 5 cyclones in ERA-Interim is shown by the contours in Fig. 1a. As in Chang (2017), the ERA-Interim climatology has been interpolated to the common $2.5^{\circ} \times$ $2.5^{\circ}$ grid and smoothed using a 9-point $(3 \times 3)$ spatial filter to facilitate comparisons with the multimodel ensemble mean climatology. For comparison, the climatological distribution of all cyclones is also shown in color shading. In general, cyclones occur over most regions poleward of $20^{\circ} \mathrm{N}$ including continental regions. Those with extreme winds are found only over the midlatitude oceans, near the oceanic peaks in the distribution of all cyclones. As expected, there are two peaks - one in the Pacific and one in the Atlantic. The multimodel mean (Fig. 1b) shows the same two peaks. The model climatology appears broader, and, over the Atlantic, extends further to the southwest toward the east coast of North America.

Under the RCP8.5 scenario, by the end of the twentyfirst century, 18 of the 19 models project a decrease in the number of top 5 cyclones (cyan bars in Fig. 2a) in the $\mathrm{NH}$, with 10 models projecting changes that are statistically significant at the $95 \%$ level based on year-to-year variability. The multimodel mean projects a decrease of about $16.8 \% \pm 7.6 \%$ (95\% uncertainties estimated based on model-to-model differences). These numerical figures are listed in Table 4 for reference.

The spatial distribution of the projected decrease in cyclone frequency is shown in Fig. 1c. Over the Atlantic $\left(90^{\circ} \mathrm{W}-30^{\circ} \mathrm{E}, 30^{\circ}-70^{\circ} \mathrm{N}\right), 17$ of the 19 models project a decrease (Fig. 2b), with a multimodel mean of $21.5 \% \pm$ $9.4 \%$, and 8 models projecting statistically significant decreases. Over the Pacific $\left(120^{\circ} \mathrm{E}-120^{\circ} \mathrm{W}, 30^{\circ}-70^{\circ} \mathrm{N}\right)$, there is also model consensus, but the projection is largely a northeastward shift (Fig. 1c). Nevertheless, over the entire basin, 14 of the 19 models project a decrease in the total number of extreme cyclones, with 6 models projecting a statistically significant decrease (Fig. 2b), with a multimodel mean decrease of $13.1 \% \pm 9.1 \%$. Over the western Pacific $\left(120^{\circ} \mathrm{E}-180^{\circ}\right), 17$ of the 19 models project a decrease (with 12 being significant; see Fig. 2c), with a multimodel mean decrease of $19.4 \% \pm 8.8 \%$. Over the northeastern Pacific $\left(180^{\circ}-120^{\circ} \mathrm{W}, 40^{\circ}-70^{\circ} \mathrm{N}\right), 12$ of the 19 models project an increase (note that 12 of 19 projecting the same sign is not significant at the $95 \%$ level based on a random binomial test, while 14 or more out of 19 projecting the same sign is significant), with a multimodel mean projection of $+11.2 \% \pm 16.7 \%$.
Results for the even more extreme cyclones (top 1 per month) are consistent, with 16 of the 19 models projecting a mean decrease of $17.6 \% \pm 11.4 \%$ (with 5 models projecting a significant decrease; see Fig. 2a, orange bars). The spatial distributions of the projected changes are also quite similar (Fig. 3c).

From Fig. 2, MRI-CGCM3 (model number 18) appears to be an outlier projecting much larger decreases than all other models. To see whether this has a significant impact on the multimodel mean, the mean for the 18 other models are computed and compared to Fig. 1c. The results (not shown) strongly resemble Fig. 1c, which confirms that even if this model is removed, the multimodel mean projected changes are similar.

The statistics for extreme winds corresponding to the top 5 cyclones are shown in Figs. 1d-f. The ERA-Interim climatology for frequency of occurrence of winds over $27.7 \mathrm{~m} \mathrm{~s}^{-1}$ is shown in Fig. 1d. The maximum frequency occurs within the masked region over Greenland. Other than that, the maxima are located over the central North Pacific and North Atlantic to the southeast of Greenland, as well as a small region of occurrence over the Bay of Alaska.

The multimodel ensemble mean shows a much broader distribution with winds associated with top 5 cyclones extending as far south as $30^{\circ} \mathrm{N}$ in the Pacific and just south of $40^{\circ} \mathrm{N}$ in the Atlantic. The apparent much higher frequency of occurrence of such winds in the multimodel mean is related to model resolution. Since extreme winds are computed at the native grid of each model, for lower-resolution models, each occurrence is counted for a larger area, thus the area-averaged frequency of occurrence is higher for low-resolution models. Thus the multimodel mean shown in Fig. 1e reflects more strongly the patterns of the lower-resolution models. Nevertheless, the strong model agreement in the sign of the change (Fig. 1f) suggests that similar changes are found in both the high- and low-resolution models. In addition, the projected change in the frequency of extreme winds for each model (as a percentage change) over the entire $\mathrm{NH}$ (excluding the masked area in Fig. 1d) is computed and plotted against projected percentage change in the number of extreme cyclones (Fig. 4a). The two show a very tight correlation, demonstrating that the results for change in extreme cyclone frequency are likely not sensitive to the cyclonetracking algorithm, since the wind statistics themselves display very similar changes. This is not only the case for the $\mathrm{NH}$ as a whole (Fig. 4a), but also for each individual basin and even parts of a basin (Fig. 5), with correlations of 0.88 or above between the two quantities.

Finally, we examine the impacts of ignoring extreme winds in the vicinity of Greenland. Clearly the main 


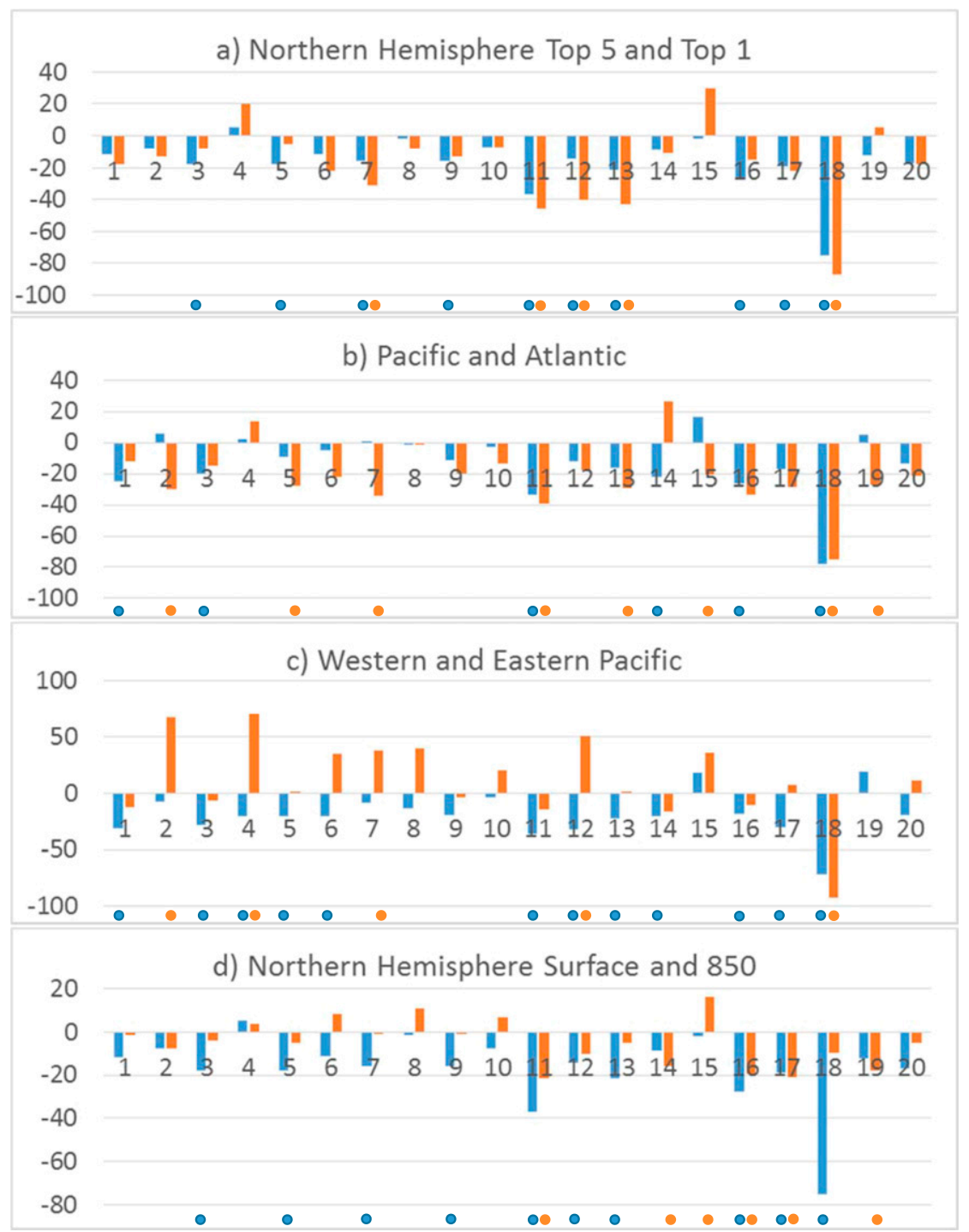

FIG. 2. (a) Projected percentage change in the number of extreme cyclones in the NH (cyan for top 5 and orange for top 1). The model numbers correspond to Table 1. Number 20 corresponds to the multimodel mean. (b) As in (a), but for top 5 cyclones in the Pacific (cyan bars) and the Atlantic (orange bars). (c) As in (b), but for the western (cyan) and eastern (orange) Pacific. (d) As in (a), but the orange bars represent the change of top 5 cyclones at the $850-\mathrm{hPa}$ level. Colored dots near the bottom of each panel denote model-projected changes that are statistically significant at the 95\% level based on a Student's $t$ test.

impact is over the Atlantic. We have computed the change in the frequency of winds above the thresholds listed in Table 3 for the Atlantic, but including the wind within the masked region. The percentage change for each model is plotted against the projected percentage change when the wind is excluded (Fig. 6). The correlation between the two quantities is 0.98 , with all models that project decreases in extreme wind frequency showing similarly large (or even larger) decreases. This suggests that the inclusion (or exclusion) of winds over the masked region will not significantly impact the changes over the Atlantic. However, if those winds are included, the threshold for extreme cyclones will increase, and more of the extreme cyclones will be located in the Atlantic and fewer will be located in the Pacific. Since the projected percentage decrease in the Atlantic is larger than that for the $\mathrm{NH}$ mean, this will likely give rise to a slightly larger percentage decrease in the $\mathrm{NH}$ as a whole.

\section{b. Cyclones with extreme 850-hPa winds}

Over the $\mathrm{NH}$, the projected change in the number of cyclones with extreme $850-\mathrm{hPa}$ winds are shown in 
TABLE 4. Climatology (1980-99) and projected change (2081-2100 minus 1980-99) of extreme cyclones, using a threshold corresponding to a top 5 or top 1 cyclone per winter (from November to March) month for each model (see Table 3). The climatology and change are quantified by number of cyclones per month, but the rightmost column shows the projected change in percent. The uncertainty ranges correspond to the $95 \%$ significant limits based on a two-tailed Student's $t$ test based on model-to-model variability.

\begin{tabular}{|c|c|c|c|c|}
\hline & & \multicolumn{3}{|c|}{ CMIP5 } \\
\hline & ERA-Interim climatology & Climatology & Change & Percent change \\
\hline \multicolumn{5}{|c|}{ Top 5 cyclones, near-surface wind } \\
\hline NH & 5 & 5 & $-0.84 \pm 0.38$ & $-17 \% \pm 7.6 \%$ \\
\hline Pacific & 3.04 & 2.82 & $-0.30 \pm 0.18$ & $-13 \% \pm 9.1 \%$ \\
\hline Western Pacific & 1.88 & 1.84 & $-0.34 \pm 0.12$ & $-19 \% \pm 8.8 \%$ \\
\hline Eastern Pacific & 1.40 & 1.02 & $0.15 \pm 0.12$ & $11.2 \% \pm 16.7 \%$ \\
\hline Atlantic & 1.95 & 2.12 & $-0.54 \pm 0.34$ & $-21 \% \pm 9.4 \%$ \\
\hline \multicolumn{5}{|c|}{ Top 1 cyclones, near-surface wind } \\
\hline NH & 1 & 1 & $-0.18 \pm 0.11$ & $-18 \% \pm 11.4 \%$ \\
\hline \multicolumn{5}{|c|}{ Top 5 cyclones, $850-\mathrm{hPa}$ wind } \\
\hline NH & 5 & 5 & $-0.25 \pm 0.25$ & $-5.0 \% \pm 5.0 \%$ \\
\hline \multicolumn{5}{|c|}{ Top 1 cyclones, $850-\mathrm{hPa}$ wind } \\
\hline NH & 1 & 1 & $0.0 \pm 0.10$ & $0.0 \% \pm 10.2 \%$ \\
\hline
\end{tabular}

Fig. 2d (orange bars). Overall, 14 of the 19 models project a decrease, with 5 models projecting a significant decrease and 1 model projecting a significant increase, and a multimodel projected decrease of $5.0 \% \pm 5.0 \%$. We have also examined 7 other models that provided pressure-level data (Table 1, models A1-A7), and 5 of those 7 models also project a decrease. While these changes are substantially smaller than those projected for cyclones with extreme near-surface winds, and are just not statistically significant at the $95 \%$ level in terms of model-to-model variability, 5 or more models (out of 19) projecting statistically significant changes of the same sign has a probability of less than $0.02 \%$ for random samples. Thus the ensemble as a whole does indicate a small decrease in the frequency of these cyclones. Projected percentage changes for surface and 850-hPa extreme cyclones for each model are plotted against each other in Fig. 4b. The correlation between these two quantities is only modest $(0.47$, significant at the $95 \%$ level), but becomes much higher (0.69) if the outlier (MRI-CGCM3) is removed. Note that most of the points are below the one-to-one line, indicating that most models project more negative changes for surface extreme cyclones than $850-\mathrm{hPa}$ extreme cyclones.

The climatological spatial distribution of these cyclones is shown by contours in Fig. 7a for ERA-Interim and Fig. 7b for CMIP5 models. Compared to the distribution of all cyclones (shading), cyclones with extreme winds at $850 \mathrm{hPa}$ are again only found over the midlatitude oceans but in this case a bit south of the oceanic peaks in the distribution of all cyclones. Projected changes are shown in Fig. 7c. Over the Pacific, the northeastward shift found for extreme surface cyclones (Fig. 1c) is also found. However, note that the contour interval used in Fig. $7 \mathrm{c}$ is $40 \%$ of that used in Fig. 1c, again indicating that multimodel projected changes for $850 \mathrm{hPa}$ are not as large as those for surface cyclones.

Over the Atlantic, the multimodel mean does not show a clear pattern of change at $850 \mathrm{hPa}$ (Fig. 7c). There are some indications of slight strengthening just off the east coast of North America, consistent with the findings of Colle et al. (2013), as well as an eastward extension toward Europe, with slight decrease in stormtrack activity on the northern and southern flanks consistent with the results of Zappa et al. (2013).

The spatial pattern of projected change in cyclone frequency is supported by that of the projected change in the frequency of the wind above the threshold of a top $5 \mathrm{cy}-$ clone per month (Fig. 7f). Averaged over the NH, the projected percentage change in the frequency of these extreme winds is well correlated with the projected percentage change in the number of extreme cyclones (Fig. 4c). The projected percentage change in the frequency of extreme winds at $850 \mathrm{hPa}$ is also significantly correlated with the projected percentage change in the frequency of extreme near-surface winds $(r=0.59$; Fig. 4d), although it is clear that most CMIP5 models project more negative changes in the frequency of extreme near-surface wind than that at $850 \mathrm{hPa}$ consistent with results for projected changes in cyclone frequencies (Fig. 4b).

For the more extreme (top 1 per month) cyclones, only 10 of the 19 models project a decrease in the number of such cyclones over the $\mathrm{NH}$ at $850 \mathrm{hPa}$, with a multimodel ensemble mean projection of $0.0 \% \pm$ $10.2 \%$. The model-to-model difference in the projected change is highly correlated with projected change in the number of top 1 surface cyclones $(r=0.75)$. The spatial pattern of the projected change in top 1 cyclones (Fig. 3f) is very similar to the pattern projected for top 5 cyclones (Fig. 7c). 
Top 1 Surface Cyc

Top 1850 Cyc

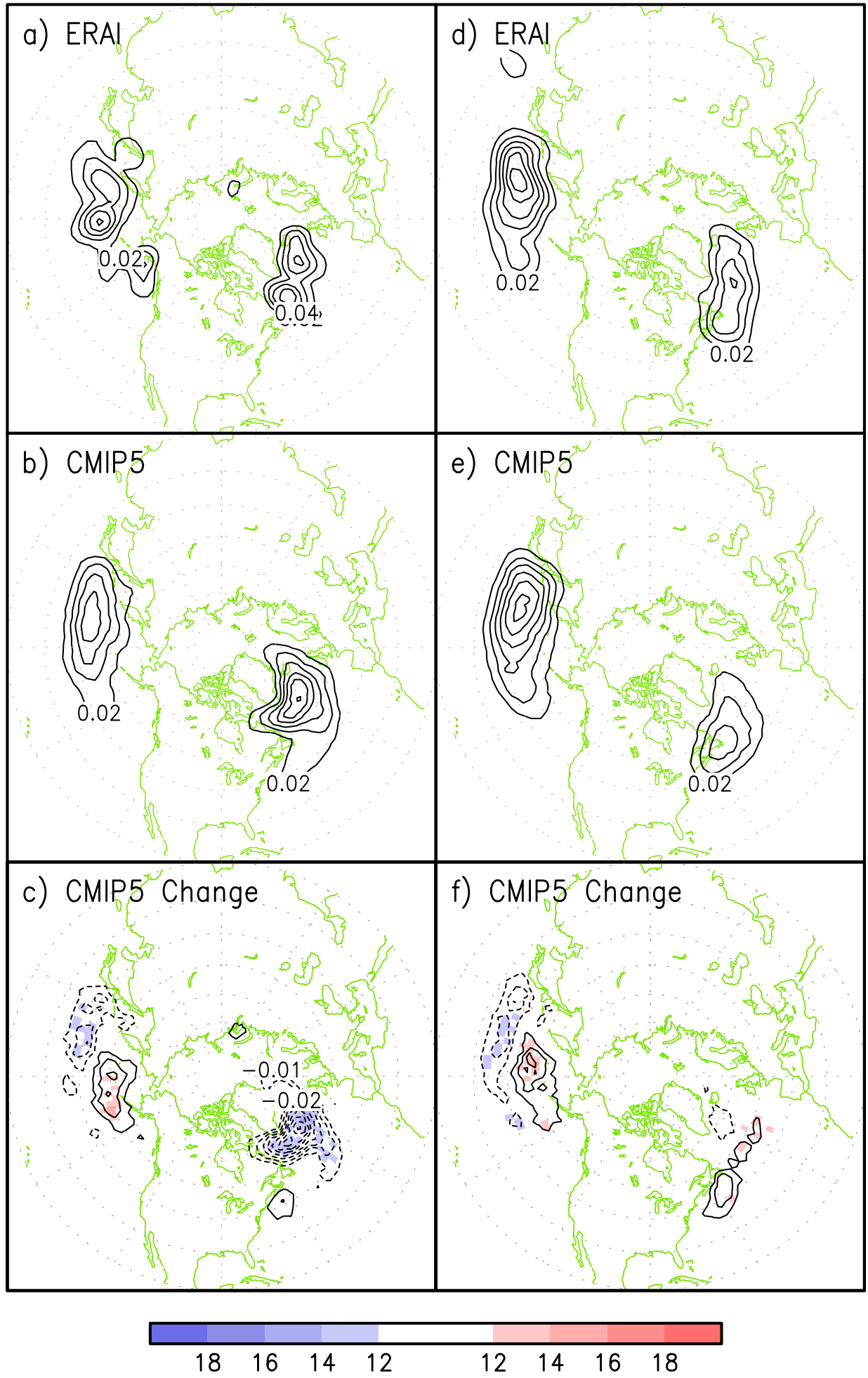

FIG. 3. (a)-(c) As in Figs. 1a-c, but for top 1 cyclones with extreme near-surface winds. Contour intervals are $0.02 \%$ in (a) and (b), and $0.01 \%$ in (c). (d)-(f) As in (a)-(c) but for top 1 cyclones with extreme $850-\mathrm{hPa}$ winds (cf. Figs. 7a-c). 
a) Surface Winds vs. Cyclones (NH) $(r=0.94)$

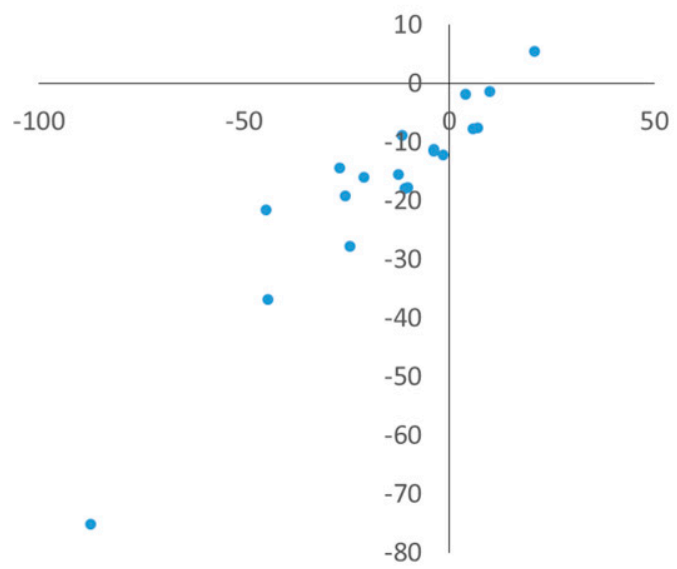

b) 850 vs. Surface Cyclones (NH) ( $r=0.47)$

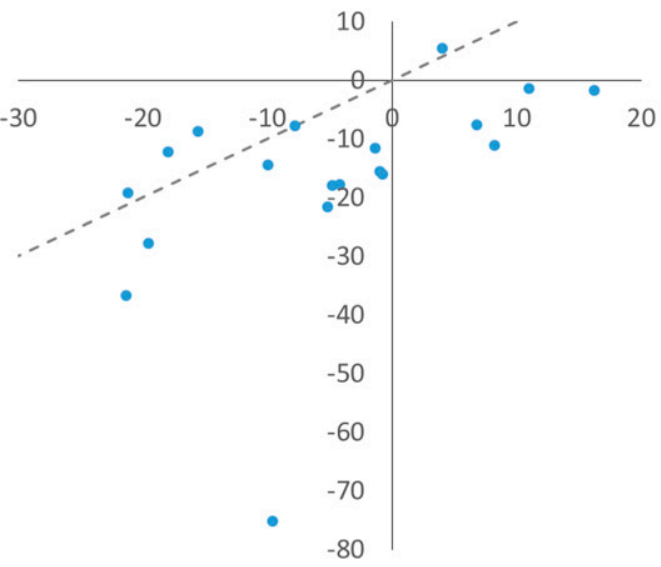

c) 850 Winds vs. Cyclones $(\mathrm{NH})(\mathrm{r}=0.80)$

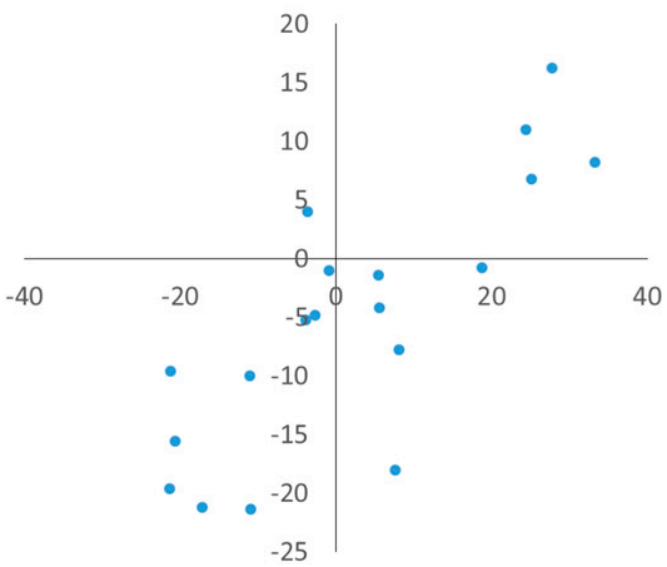

d) 850 vs. Surface Winds (NH) ( $r=0.59)$

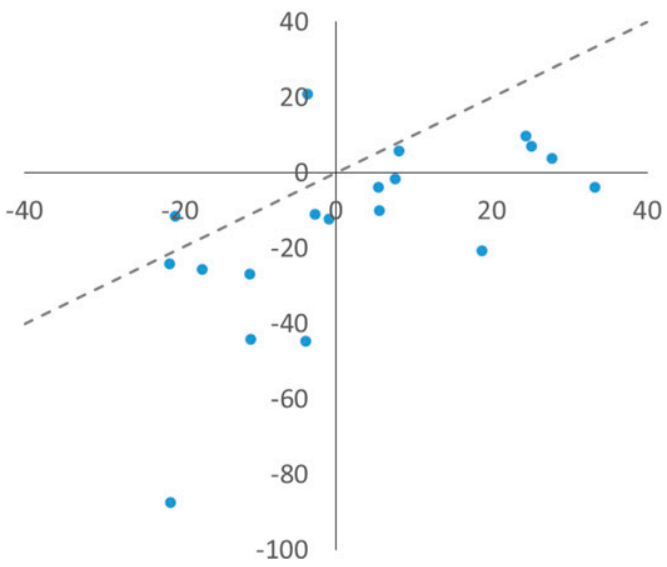

FIG. 4. Scatterplots relating projected changes in two quantities from each model (\%). The first quantity is the abscissa while the second quantity is the ordinate. All panels are for top 5 cyclones averaged over the entire $\mathrm{NH}$. (a) Frequency of extreme near-surface winds vs number of surface extreme cyclones. (b) Number of 850-hPa extreme cyclones vs number of extreme surface cyclones. (c) Frequency of extreme 850-hPa winds vs number of extreme 850 -hPa cyclones. (d) Frequency of extreme $850-\mathrm{hPa}$ winds vs frequency of extreme near-surface winds. The dashed line in (b) and (d) corresponds to the 1-to-1 line. All correlations shown are statistically significant at the $95 \%$ level.

\section{Summary and discussion}

In this study, CMIP5 simulations have been examined to see how extreme winter cyclones are projected to change in the $\mathrm{NH}$ under the high-emission RCP8.5 scenario. Extreme cyclones are defined in terms of wind intensity at either the near-surface or $850-\mathrm{hPa}$ level. Extreme wind thresholds are model dependent, corresponding to top 5 or top 1 cyclones per winter month in the entire NH during the historical period.

For cyclones with extreme near-surface winds, CMIP5 models project a significant decrease in the number of such cyclones, with a 19-model-mean decrease of about $17 \%$ for the entire $\mathrm{NH}$ toward the end of the twenty-first century. Eighteen of the 19 models project a decrease, and 10 of the projections are statistically significant. The projected decrease is larger in the Atlantic (about 21\%). Over the Pacific, apart from an overall decrease (of about $13 \%$ ), there is a northeastward shift of the extreme cyclone activity, with models projecting a decrease over the western Pacific and an increase over the northeastern Pacific. Results for top 1 cyclones are similar. These projections are supported by the projections of changes in the extreme wind frequency that show very similar patterns to those projected for changes in extreme cyclone frequency.

At $850 \mathrm{hPa}$, CMIP5 models still project a small overall decrease of top 5 cyclones in the $\mathrm{NH}$ of about $5 \%$, with 14 of the 19 models projecting a decrease. Models also project a clear northeastward shift in the Pacific. Over 
a) Surface Winds vs. Cyclones (PAC)

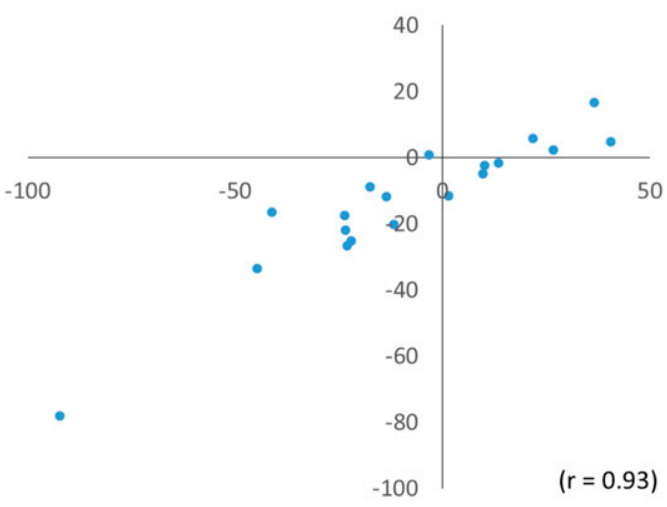

b) Surface Winds vs. Cyclones (ATL)

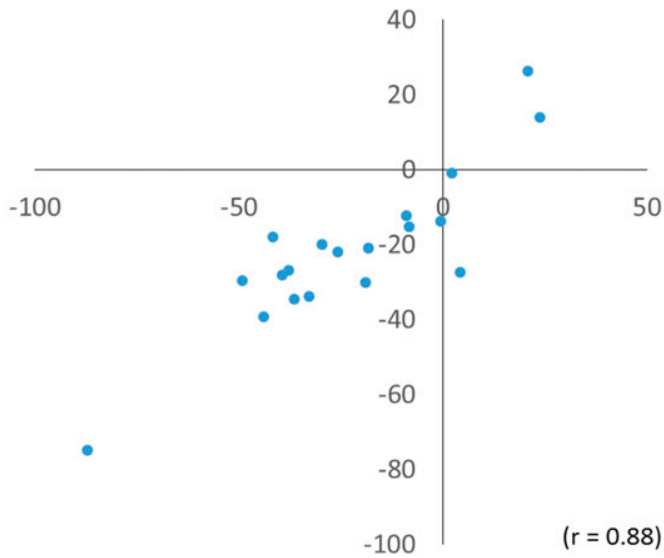

c) Surface Winds vs. Cyclones (W Pac)

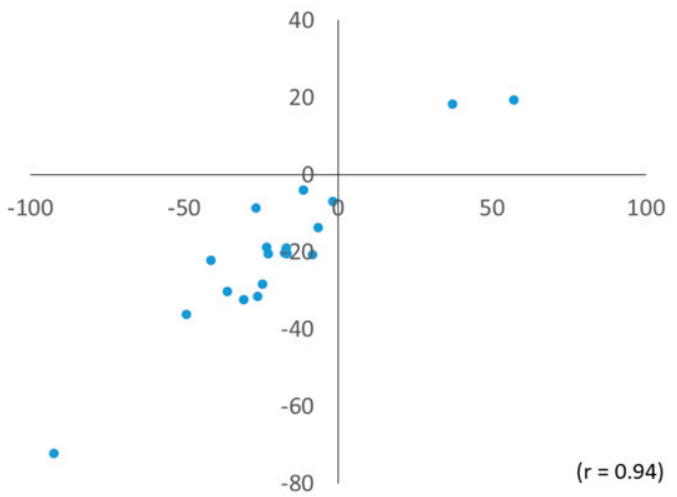

d) Surface Winds vs. Cyclones (E Pac)

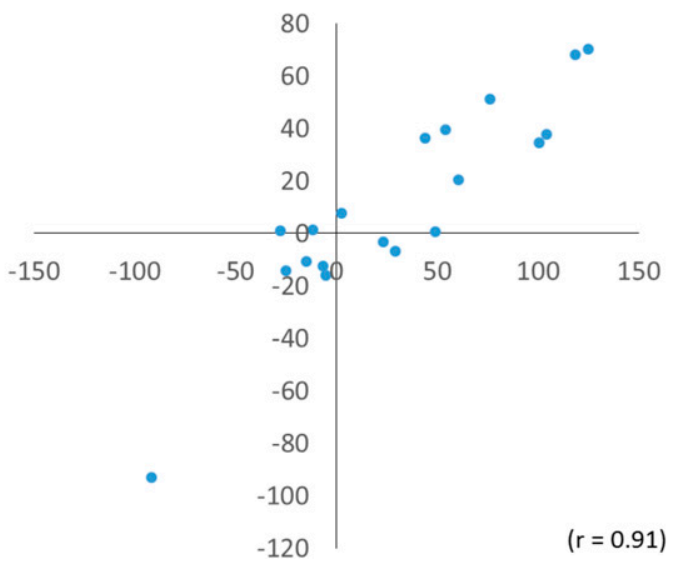

FIG. 5. As in Fig. 4a, but for (a) Pacific, (b) Atlantic, (c) western Pacific, and (d) eastern Pacific.

the Atlantic, model agreement is much weaker, with some indications of an increase near the east coast of North America extending toward Europe and decreases toward the northern and southern flanks.

Comparing to previous studies, the current results are rather different from those studies that used SLP depth as intensity measures for cyclones. As discussed in Chang (2014), using SLP perturbations (as in Chang et al. 2012) as the intensity metric highlights the decrease in deep cyclones over the western Pacific and across North America, while using total SLP (as in Mizuta 2012) highlights a strong increase in deep cyclones over the northeastern Pacific that is likely associated with the projected deepening of the Aleutian low. Both suggested some slight reduction in the Atlantic, but much less than the extent shown by the decrease in the frequency of cyclones with strong near-surface winds. The current results are more consistent with those for explosive cyclones. The projections of a northeastward shift in the Pacific and a significant decrease in extreme surface cyclones in the Atlantic are more or less consistent with the results of Seiler and
Zwiers (2016). However, here we also find an overall decrease in intense cyclones over the Pacific on top of the northeastward shift, and the region of decrease in the Atlantic is located far downstream of the region that Seiler and Zweirs found for the decrease in the frequency of explosive cyclones (over the western Atlantic just off the coast of North America). Seiler and Zwiers (2016) also showed that the mean vorticity (at $850 \mathrm{hPa}$ ) of explosive cyclones is projected to increase in the Atlantic-this is consistent with our finding that the $850-\mathrm{hPa}$ extreme wind frequency may increase off the east coast of North America extending toward Europe, but similar increases in extreme winds are not found near the surface.

Comparing the two hemispheres, Chang (2017) showed that CMIP5 models project a significant increase in the number of cyclones with extreme winds in the $\mathrm{SH}$ in all seasons, both near the surface and at $850 \mathrm{hPa}$. This interhemispheric difference is likely related to the projected polar amplification of warming in the $\mathrm{NH}$ (e.g., Holland and Bitz 2003) that is absent in the SH. As discussed above, in the $\mathrm{SH}$, the upper-tropospheric 


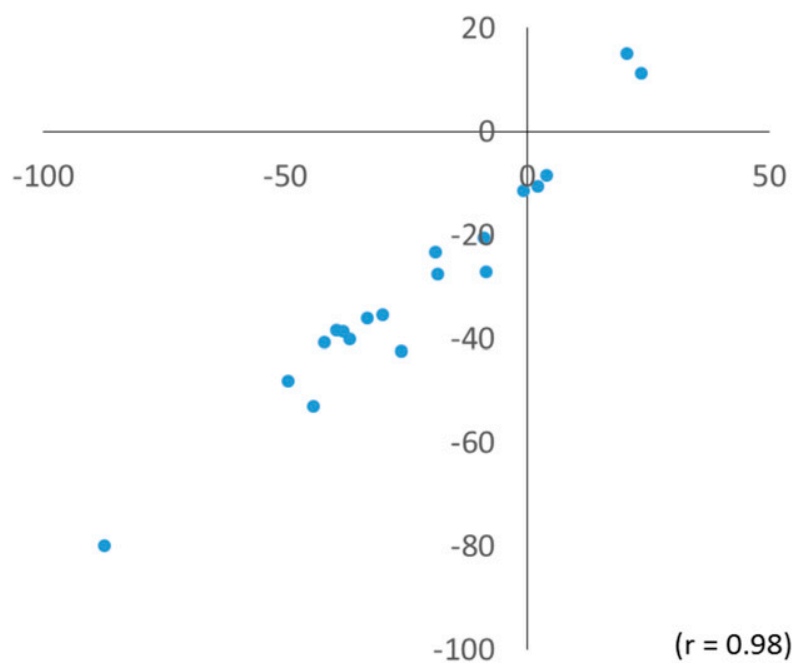

FIG. 6. Scatterplot relating projected percentage change in masked vs unmasked extreme (top 5 cyclones) near-surface winds in the Atlantic.

temperature gradient is projected to increase, leading to an overall increase in baroclinicity, as indicated by a projected increase in the mean available potential energy (MAPE; e.g., O'Gorman 2010), and storm-track activity is projected to increase throughout the troposphere (e.g., Chang et al. 2012). On the other hand, in the $\mathrm{NH}$, with polar amplification, lower-tropospheric baroclinicity is projected to decrease significantly. Hence storm-track activity is projected to increase in the upper troposphere but decrease in the lower troposphere (Chang et al. 2012; Harvey et al. 2012). The projected overall decrease in the frequency of cyclones with extreme near-surface winds in the $\mathrm{NH}$ is likely related to the projection of a significant decrease in the lower-tropospheric meridional temperature gradient, while the northeastward shift in the Pacific is likely related to a projected northward shift of the Pacific jet by CMIP5 models (e.g., Mizuta 2012; Seiler and Zwiers 2016). Nevertheless, while the projected changes in extreme cyclones are qualitatively consistent with the projected changes in the large-scale flow, consistent with Chang (2017), we do not find any significant correlation between model-to-model differences in the projected change in extreme cyclone (or wind) frequency and difference in baroclinicity metrics such as MAPE, meridional temperature gradient, or mean jet speed, and thus what factors quantitatively control the changes in extreme wind frequency are still not clear.

Another interesting finding is the differences in projections between the near surface and $850 \mathrm{hPa}$. These differences are also reflected in the projection of changes in extreme wind frequency. Our results suggest that projected changes in near-surface extreme winds are more negative than those at $850 \mathrm{hPa}$. This is consistent with the findings of Chang (2017), who showed that CMIP5 models project larger increases in the frequency of cyclones with extreme winds at $850 \mathrm{hPa}$ than at the surface in the SH. Our hypothesis is that this may be due to the vertical structure of the projected change in baroclinicity. In the $\mathrm{NH}$, the largest decrease in baroclinicity is found near the surface, while the maximum increase in baroclinicity is projected to be in the upper troposphere, hence one might expect increasingly positive change as one proceeds upward from the surface.

There are some indications from ERA-Interim data that something like this may already be happening. As discussed above, Wang et al. (2017) found that over the past 36 years, the Atlantic storm track (in terms of variance statistics and eddy kinetic energy) has weakened significantly. This is likely related to enhanced highlatitude warming near the surface. The corresponding changes in the frequency of extreme winds $\left(>27.7 \mathrm{~m} \mathrm{~s}^{-1}\right.$ at $10 \mathrm{~m}$ and $>45.3 \mathrm{~m} \mathrm{~s}^{-1}$ at $850 \mathrm{hPa}$ ) are shown in Fig. 8 . Since extreme wind statistics are rather noisy, only scattered grid boxes show statistically significant changes (even at the $90 \%$ level). Nevertheless, averaged over the entire region, ERA-Interim data show a decrease in extreme wind frequency of about $20 \%$ at $10 \mathrm{~m}$, but the decrease at $850 \mathrm{hPa}$ is only about $6 \%$ (but note that both changes are not statistically significant), consistent with more cancellation between positive and negative changes shown in Fig. 8. Nevertheless, one should be skeptical about these changes, since trends found in reanalysis data may suffer from changes in the amount and type of observations assimilated into the reanalysis system (e.g., Bengtsson et al. 2004). More detailed dynamical studies should be conducted to examine the hypothesis posed above and to better understand the differences between $850-\mathrm{hPa}$ and nearsurface projections. Taken on their face value, these results suggest that projected changes at the $850-\mathrm{hPa}$ level may not be a good proxy for projected changes near the surface, consistent with the results of Booth et al. (2017).

The high correlation between projected changes in extreme cyclones and extreme wind frequency might suggest that one can simply analyze the extreme wind statistics and bypass the cyclone statistics entirely. Nevertheless, by examining the weather systems that are responsible for these winds in more detail, one may gain more insight about the physical processes that give rise to the projected changes, and future work will focus on this issue.

One point to keep in mind is that CMIP5 models may not be able to well resolve the impacts of mesoscale features and diabatic heating on cyclones, including the 


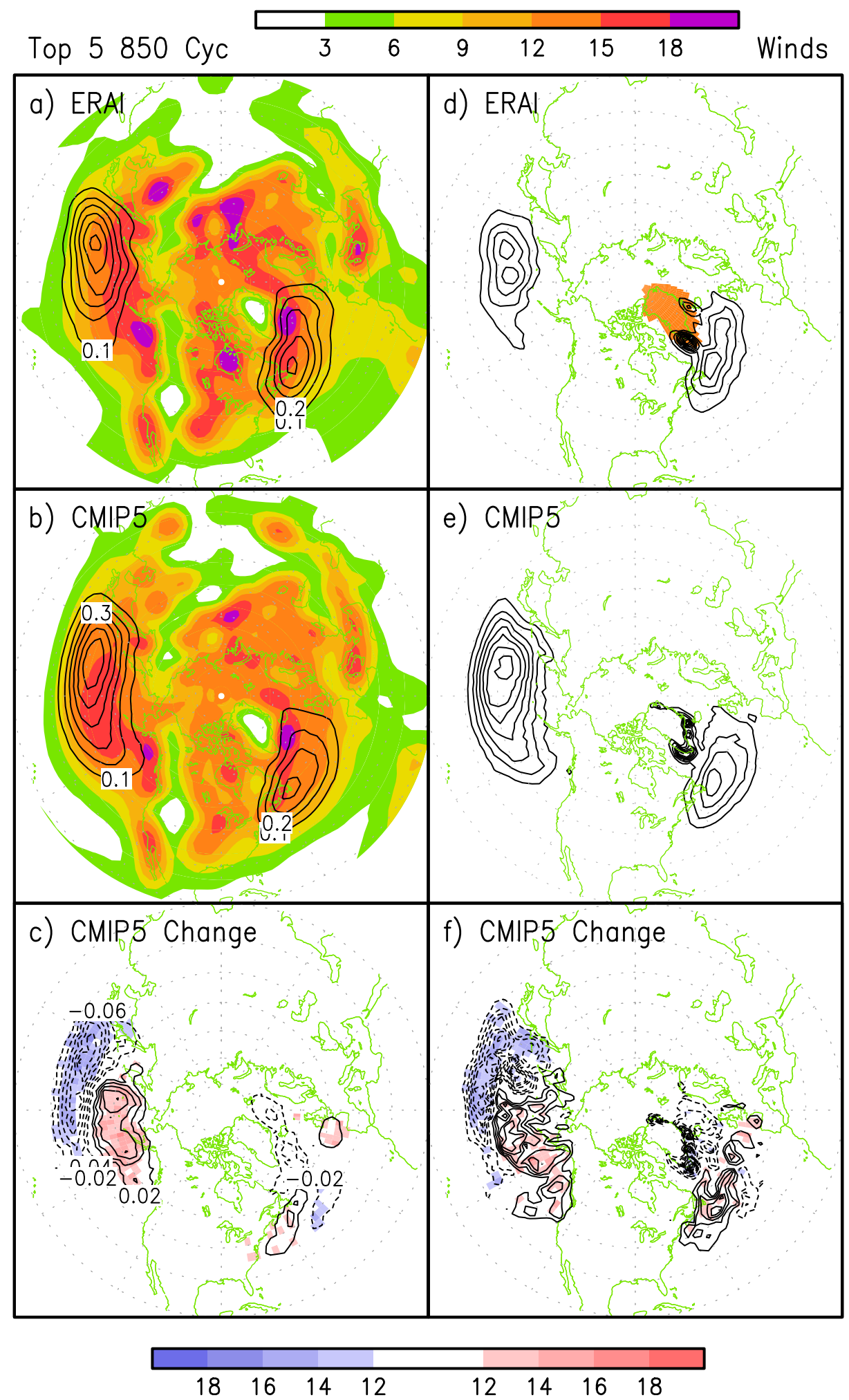

FIG. 7. As in Fig. 1, but for cyclones with extreme (top 5) winds at $850 \mathrm{hPa}$. The contour interval is $0.1 \%$ in (a) and (b), $0.02 \%$ in (c)-(e), and $0.004 \%$ in (f). 
a) $10 \mathrm{~m}$ Wind Clim

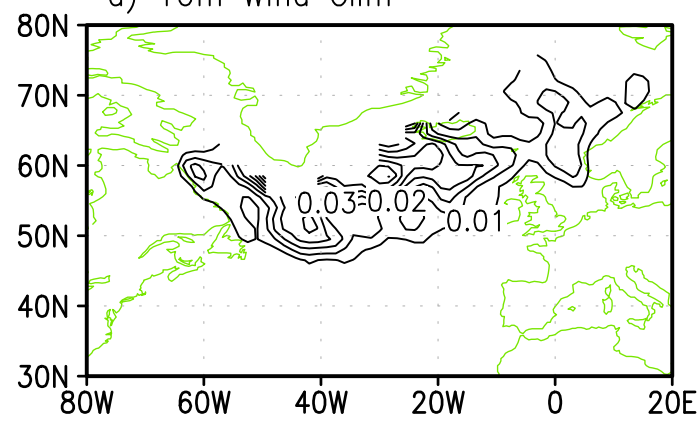

b) $10 \mathrm{~m}$ Wind Change

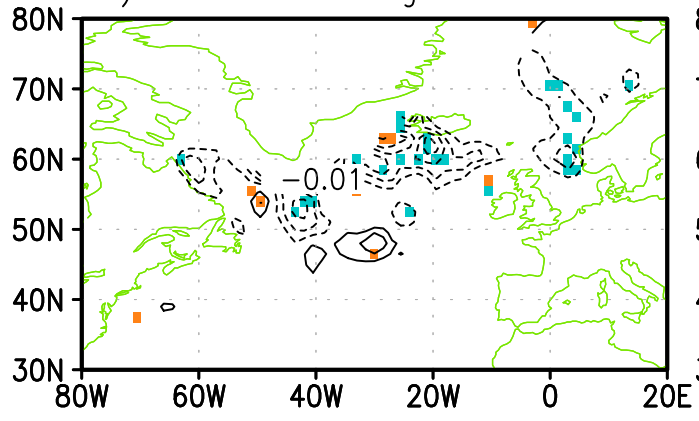

c) 850 Wind Clim

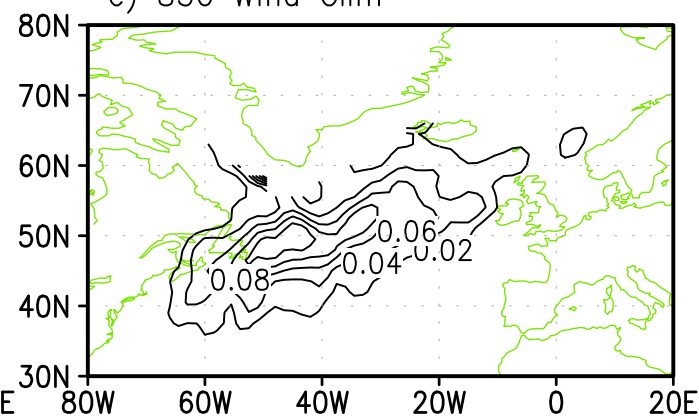

d) 850 Wind Change

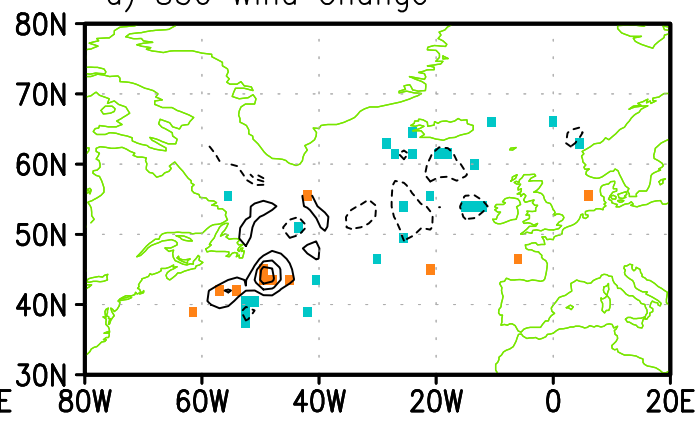

FIG. 8. (a) Climatological frequency of extreme $10-\mathrm{m}$ wind $\left(>27.7 \mathrm{~m} \mathrm{~s}^{-1}\right)$ during the extended cool seasons of 1979/80-1996/97 (contour interval is 0.01\%) based on ERA-Interim data. (b) Change in frequency of 10-m extreme wind between the periods of 1979/80-1996/97 and 1997/98-2014/15 (contour interval is 0.01\%). (c),(d) As in (a) and (b) but for $850-\mathrm{hPa}$ wind $>45.3 \mathrm{~m} \mathrm{~s}^{-1}$ (contour interval is $0.02 \%$ ). Grid boxes over which the change is significant at the $90 \%$ level are indicated by cyan (negative) and orange (positive) shading.

potential impacts of an increase in atmospheric moisture content under global warming (e.g., Willison et al. 2013), as well as the impacts of mesoscale features such as sting jets (e.g., Martínez-Alvarado et al. 2018). Moreover, nearsurface wind gusts may be better represented by modelpredicted $850-\mathrm{hPa}$ wind speed rather than near-surface wind speed, given that winds at the top of the boundary layer represent a source of momentum available for transport through the boundary layer by eddies (e.g., Sheridan 2011). Nevertheless, these results should serve as a useful baseline that can be compared to results from high-resolution simulations that will be conducted under the High Resolution Model Intercomparison Project (HighResMIP) for CMIP6 (Haarsma et al. 2016), as well as downscaling experiments using mesoscale resolving models that should be able to better resolve the diabatic and mesoscale impacts on cyclone development.

Finally, even though overall the number of extreme cyclones is projected to decrease, most of the projected decrease occurs over oceanic regions. Over the Pacific, extreme cyclone activity is projected to shift northeastward closer to northwestern North America. Over the Atlantic, there are hints of a slight increase in extreme cyclone activity close to the east coast of North America. Thus there could be increased cyclone impacts over populated regions.
However, such regional details are unlikely to be well captured by CMIP5 models, and further studies using higherresolution model simulations are needed (e.g., Seiler et al. 2018). Moreover, given that in this study extreme cyclones are defined by extreme near-surface winds using a hemispheric threshold, and these occur mainly over the oceans, an entirely different strategy in cyclone selection (e.g., winds based on local percentile thresholds instead of hemispheric thresholds) will be required to document projected changes in cyclones with extreme near-surface winds over land, which is a subject of current investigation.

Acknowledgments. The author would like to thank the Earth System Grid and the climate modeling centers for providing the CMIP5 data, ECMWF for providing the ERA-Interim reanalysis data, and three anonymous reviewers for comments that helped clarify this manuscript. This research is supported by NSF Grant AGS1261311 and NASA Grant NNX16AG32G.

\section{APPENDIX}

\section{Analyses of Model-Derived 10-m Winds}

Twelve of the 19 models analyzed in this study also provided derived 10-m winds at 3-hourly frequency for 
a) Top $510 \mathrm{~m}$ vs near surface wind (NH)

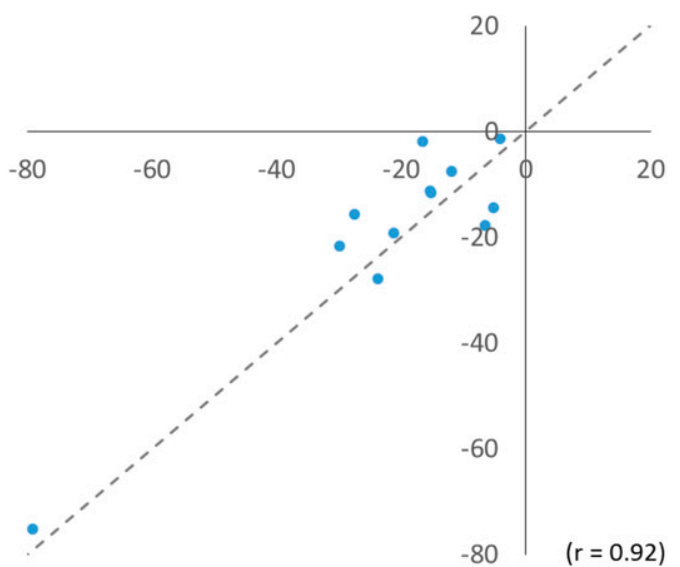

b) Top $510 m$ vs near surface wind (ATL)

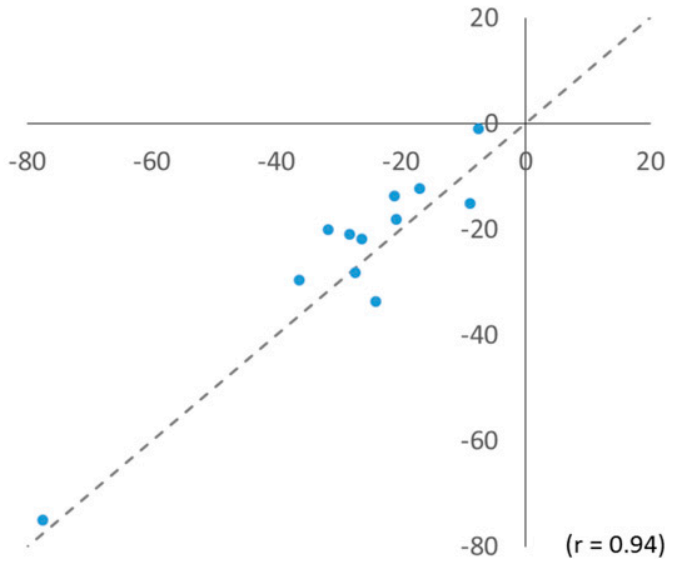

FIG. A1. Scatterplot relating projected percentage change in top 5 cyclones with extreme $10-\mathrm{m}$ wind and top 5 cyclones with extreme near-surface (lowest model level) wind for the (a) NH and (b) North Atlantic.

our analysis periods. Similar analyses have been conducted using these winds in place of the lowest modellevel winds. Since we only have cyclone positions every $6 \mathrm{~h}$, the analyses are performed at 6-hourly intervals. Thresholds corresponding to a top 5 cyclone per month for ERA-Interim and each of the 12 models can be found in the rightmost column of Table 3 . For both $10-\mathrm{m}$ wind and wind at the lowest model level, all 12 models project a decrease in the frequency of top 5 cyclones over the entire Northern Hemisphere as well as the North Atlantic (see Fig. A1), with the projected decrease based on 10-m wind being on average slightly larger than that based on the lowest model-level wind. Consistent results are also found for the Pacific (not shown).

\section{REFERENCES}

Bengtsson, L., S. Hagemann, and K. I. Hodges, 2004: Can climate trends be calculated from reanalysis data? J. Geophys. Res., 109, D11111, https://doi.org/10.1029/2004JD004536.

_ , K. I. Hodges, and N. Keenlyside, 2009: Will extratropical storms intensify in a warmer climate? J. Climate, 22, 22762301, https://doi.org/10.1175/2008JCLI2678.1.

Booth, J. F., Y.-O. Kwon, S. Ko, R. J. Small, and R. Msadek, 2017: Spatial patterns and intensity of the surface storm tracks in CMIP5 model. J. Climate, 30, 4965-4981, https://doi.org/ 10.1175/JCLI-D-16-0228.1.

Chang, E. K. M., 2014: Impacts of background field removal on CMIP5 projected changes in Pacific winter cyclone activity. J. Geophys. Res. Atmos., 119, 4626-4639, https://doi.org/ 10.1002/2013JD020746.

_ 2017: Projected significant increase in the number of extreme extratropical cyclones in the Southern Hemisphere. J. Climate, 30, 4915-4935, https://doi.org/10.1175/JCLI-D-16-0553.1.

_ Y. Yuo, and X. Xia, 2012: CMIP5 multimodel ensemble projection of storm track change under global warming. J. Geophys. Res., 117, D23118, https://doi.org/10.1029/2012JD018578.
— C.-G. Ma, C. Zheng, and A. M. W. Yau, 2016: Observed and projected decrease in Northern Hemisphere extratropical cyclone activity in summer and its impacts on maximum temperature. Geophys. Res. Lett., 43, 2200-2208, https://doi.org/ 10.1002/2016GL068172.

Christensen, J. H., and Coauthors, 2013: Climate phenomena and their relevance for future regional climate change. Climate Change 2013: The Physical Science Basis, T. F. Stocker et al., Eds., Cambridge University Press, 1217-1308, https://doi.org/ 10.1017/CBO9781107415324.028.

Colle, B. A., Z. Zhang, K. A. Lombardo, E. K. M. Chang, P. Liu, and M. Zhang, 2013: Historical evaluation and future prediction of eastern North American and western Atlantic extratropical cyclones in the CMIP5 models during the cool season. J. Climate, 26, 6882-6903, https://doi.org/10.1175/ JCLI-D-12-00498.1.

Coumou, D., J. Lehmann, and J. Beckmann, 2015: The weakening summer circulation in the Northern Hemisphere midlatitudes. Science, 348, 324-327, https://doi.org/10.1126/ science.1261768.

Gorter, W., J. H. van Angelen, J. T. M. Lenaerts, and M. R. van den Broeke, 2014: Present and future near-surface wind climate of Greenland from high resolution regional climate modeling. Climate Dyn., 42, 1595-1611, https://doi.org/ 10.1007/s00382-013-1861-2.

Haarsma, R. J., and Coauthors, 2016: High Resolution Model Intercomparison Project (HighResMIP v1.0) for CMIP6. Geosci. Model Dev., 9, 4185-4208, https://doi.org/10.5194/ gmd-9-4185-2016.

Harvey, B. J., L. C. Shaffrey, T. J. Woollings, G. Zappa, and K. I. Hodges, 2012: How large are projected 21st century storm track changes? Geophys. Res. Lett., 39, L18707, https://doi.org/ 10.1029/2012GL052873.

,-- , and,- 2014 : Equator-to-pole temperature differences and the extra-tropical storm track responses of the CMIP5 climate models. Climate Dyn., 43, 1171-1182, https:// doi.org/10.1007/s00382-013-1883-9.

Hodges, K. I., 1999: Adaptive constraints for feature tracking. Mon. Wea. Rev., 127, 1362-1373, https://doi.org/10.1175/ 1520-0493(1999)127<1362:ACFFT>2.0.CO;2. 
Holland, M. M., and C. M. Bitz, 2003: Polar amplification of climate change in coupled models. Climate Dyn., 21, 221-232, https:// doi.org/10.1007/s00382-003-0332-6.

Hoskins, B. J., and K. I. Hodges, 2002: New perspectives on the Northern Hemisphere winter storm tracks. J. Atmos. Sci., 59, 1041-1061, https://doi.org/10.1175/1520-0469(2002)059<1041: NPOTNH $>2.0 . \mathrm{CO} ; 2$.

Kunkel, K. E., D. R. Easterling, D. A. R. Kristovich, B. Gleason, L. Stoecker, and R. Smith, 2012: Meteorological causes of the secular variations in observed extreme precipitation events for the conterminous United States. J. Hydrometeor., 13, 1131-1141, https://doi.org/10.1175/JHM-D-11-0108.1.

Ma, C.-G., and E. K. M. Chang, 2017: Impacts of storm-track variations on wintertime extreme weather events over the continental United States. J. Climate, 30, 4601-4624, https:// doi.org/10.1175/JCLI-D-16-0560.1.

Martínez-Alvarado, O., S. L. Gray, N. C. G. Hart, P. A. Clark, K. Hodges, and M. J. Roberts, 2018: Increased wind risk from sting-jet windstorms with climate change. Environ. Res. Lett., 13, 044002, https://doi.org/10.1088/1748-9326/ aaae3a.

Mizuta, R., 2012: Intensification of extratropical cyclones associated with the polar jet change in the CMIP5 global warming projections. Geophys. Res. Lett., 39, L19797, https://doi.org/ 10.1029/2012GL053032.

Neu, U., and Coauthors, 2013: IMILAST: A community effort to intercompare extratropical cyclone detection and tracking algorithms. Bull. Amer. Meteor. Soc., 94, 529-547, https://doi.org/ 10.1175/BAMS-D-11-00154.1.

O'Gorman, P. A., 2010: Understanding the varied response of the extratropical storm tracks to climate change. Proc. Natl. Acad. Sci. USA, 107, 19176-19180, https://doi.org/10.1073/ pnas. 1011547107.

Raible, C. C., P. M. Della-Marta, C. Schwierz, H. Wernli, and R. Blender, 2008: Northern Hemisphere extratropical cyclones:
A comparison of detection and tracking methods and different reanalyses. Mon. Wea. Rev., 136, 880-897, https://doi.org/ 10.1175/2007MWR2143.1.

Seiler, C., and F. W. Zwiers, 2016: How will climate change affect explosive cyclones in the extratropics of the Northern Hemisphere? Climate Dyn., 46, 3633-3644, https://doi.org/10.1007/ s00382-015-2791-y.

, K. I. Hodges, and J. Scinocca, 2018: How does dynamical downscaling affect model biases and future projections of explosive extratropical cyclones along North America's Atlantic coast? Climate Dyn., 50, 677-692, https:// doi.org/10.1007/s00382-017-3634-9.

Sheridan, P., 2011: Review of techniques and research for gust forecasting and parameterization. Met Office Forecasting Research Tech. Rep. 570, 19 pp.

Våge, K., T. Spengler, H. C. Davies, and R. S. Pickart, 2009: Multievent analysis of the westerly Greenland tip jet based upon 45 winters in ERA-40. Quart. J. Roy. Meteor. Soc., 135, 19992011, https://doi.org/10.1002/qj.488.

Wang, J., H.-M. Kim, and E. K. M. Chang, 2017: Changes in Northern Hemisphere winter storm tracks under the background of Arctic amplification. J. Climate, 30, 3705-3724, https://doi.org/10.1175/ JCLI-D-16-0650.1.

Willison, J., W. A. Robinson, and G. M. Lackmann, 2013: The importance of resolving mesoscale latent heating in the North Atlantic storm track. J. Atmos. Sci., 70, 2234-2250, https://doi.org/ 10.1175/JAS-D-12-0226.1.

Yin, J. H., 2005: A consistent poleward shift of the storm tracks in simulations of 21 st century climate. Geophys. Res. Lett., 32 , L18701, https://doi.org/10.1029/2005GL023684.

Zappa, G., L. C. Shaffrey, K. I. Hodges, P. G. Sansom, and D. B. Stephenson, 2013: A multimodel assessment of future projections of North Atlantic and European extratropical cyclones in the CMIP5 climate models. J. Climate, 26, 5846-5862, https://doi.org/10.1175/JCLI-D-12-00573.1. 